\title{
The effect of salinity and compatible solutes on the biosynthesis of cyclopropane fatty acids in Pseudomonas halosaccharolytica
}

\author{
Mercedes Monteoliva-Sanchez, ${ }^{1}$ Alberto Ramos-Cormenzana ${ }^{1}$ and Nicholas J. Russell ${ }^{2 *}$ \\ ${ }^{1}$ Departamento de Microbiologia, Facultad de Farmacia, Universidad de Granada, Granada 18001, Spain \\ ${ }^{2}$ Department of Biochemistry, University of Wales, PO Box 903, Cardiff CF1 1ST, UK
}

(Received 11 March 1993; revised 10 May 1993; accepted 14 May 1993)

\begin{abstract}
The moderately halophilic eubacterium Pseudomonas halosaccharolytica has been grown at salinities over the range $5-25 \%(w / v)$, equivalent to $0.7-3.5 \mathrm{M}-\mathrm{NaCl}$, and the fatty acid composition determined in the lateexponential and stationary phases of batch culture. There was an increase in the proportion of cyclopropane fatty acids (CFA) as the cultures went into stationary phase at all salinities; the overall proportion of CFA was higher in the media containing more salt. The biosynthesis of CFA in $P$. halosaccharolytica was determined using radiolabelled $S$-adenosylmethionine as the precursor incubated in cell-free extracts prepared by breaking bacteria with a French press. Compared with the activity obtained in 100 mM-phosphate buffer, the activity of CFA synthetase was inhibited by the addition of $\mathrm{NaCl}$ or $\mathrm{KCl}$, but stimulated up to 12-fold by added glycinebetaine, with maximum activity at $3 \mathrm{M}$. Although the specific activity of CFA synthetase in lysates from cultures grown in 0.7 or 2.1 M-NaCl were similar in the presence of $3 \mathrm{M}$-glycinebetaine, the enzyme activity in low-salinity cultures was better adapted to function in $1 \mathrm{M}$-glycinebetaine. Shift-up experiments, in which CFA synthetase activity was assayed in cell-free extracts prepared at different times after increasing culture salinity from 0.7 to $2.1 \mathrm{M}-\mathrm{NaCl}$, showed that the activity of the enzyme was immediately responsive to compatible solute concentration changes and indicated that enzyme induction would not be required to achieve the salt-dependent alterations in membrane lipid CFA composition in vivo. A range of other compatible organic solutes stimulated CFA synthetase activity to a much lesser extent (1-8-fold) compared with glycinebetaine. It is suggested that a compatible solute, which is normally accumulated during osmo(halo)adaptation by an organism in order to contribute towards osmotic balance, does not behave passively towards intracellular proteins but can also stimulate enzyme activity.
\end{abstract}

\section{Introduction}

Halophilic eubacteria require $>3 \%(w / v) ~ N a C l$ and can grow in up to $25 \%(\mathrm{w} / \mathrm{v}) \mathrm{NaCl}$ (Kushner, 1978; Larsen, 1986). They are important in the spoilage of preserved foods and in saline environments, and so the increasing consumption of 'fast' foods and problems of soil salinization of large tracts of artificially-irrigated land worldwide make studies of these bacteria timely. In particular, it is necessary to understand the mechanisms which these bacteria utilize in order to enable them to withstand the osmotic and ionic stresses imposed by high salinity.

The two main ways in which eubacteria (and other micro-organisms) respond to raised external salinity is by

* Author for correspondence. Tel. 0222-874120; fax 0222-874116.

Abbreviation: CFA, cyclopropane fatty acid(s). the accumulation of intracellular compatible solutes and by modification of membrane composition and function (Russell, 1989a, 1992; Csonka, 1989). In aerobic eubacterial halophiles the compatible solutes most commonly accumulated as major components are the amino acids glycinebetaine, ectoine and glutamate; smaller amounts of the sugar trehalose or other polyols and amino acids may be present (Imhoff, 1986; Regev et al., 1990; Wohlfarth et al., 1990). The compatible solute composition usually depends on the type of culture medium used and in many species, including Pseudomonas halosaccharolytica (Severin et al., 1992), glycinebetaine predominates when complex broth media are employed. There is good evidence that the membrane is involved in the sensing and response to external salinity (Russell \& Kogut, 1985; Stock et al., 1989; Csonka \& Hanson, 1991), and usually the lipid composition is altered during haloadaptation. Two types of lipid change are observed: in the first, the phospholipid 
composition is altered so as to preserve the integrity of the bilayer phase; in the second, there is an alteration in the fatty acid composition of the lipids (Russell, 1989 $a$, 1992). The most frequently reported change in fatty acid composition of Gram-negative eubacteria, including $P$. halosaccharolytica (Monteoliva-Sanchez \& RamosCormenzana, 1987), is a salt-dependent increase in the proportion of cyclopropane fatty acids which may also increase as batch cultures enter the stationary phase of growth.

Cyclopropane fatty acids (CFA) are formed by the addition of a methylene group across the double bond of a monounsaturated fatty acid (Harwood \& Russell, 1984). The function of CFA remains unclear, and early proposals that they protect fatty acid double bonds against oxidation have not been substantiated (Russell, $1989 b$ ). The cyclopropane ring rigidifies the central part of the acyl chain (Jarrell et al., 1983), and the thermal properties of CFA-containing lipids (Cronan et al., 1979) or membranes (Jarrell et al., 1983) are subtly distinct. NMR studies support the hypothesis that CFA increase the organizational stability of membranes, whilst providing a level of fluidity comparable with that of monounsaturated fatty acids (Macdonald et al., 1985). Since the CFA synthetase enzyme in different bacteria is either an integral membrane protein or it associates with the membrane and is regulated by activation or induction (Harwood \& Russell, 1984), it could well be involved in a self-balancing, salt-triggered system for modifying membrane properties when external $\mathrm{NaCl}$ and therefore internal compatible solute concentrations are increased. Therefore, we have investigated the effects of growth phase and the addition of $\mathrm{NaCl}$ and organic compatible solutes on CFA synthetase activity and the membrane lipid fatty acid composition in the moderately halophilic eubacterium. $P$. halosaccharolytica. This was selected for study because it is known to accumulate cyclopropane fatty acids (Ohno et al., 1979) and it is capable of growing over a wide range of salinities.

\section{Methods}

Bacterial strains. 'Pseudomonas halosaccharolytica' (CCM 2851) was used as the experimental organism. The quotation marks indicate that the name was not included in the Approved Lists of Bacterial Names or its supplements (Skerman et al., 1980; Moore et al., 1985).

Cultural conditions. For experimental purposes, cultures were grown in a liquid medium containing $0.5 \%$ proteose peptone (Difco), $0.5 \%$ yeast extract (Difco) and 0.2\% glucose. This medium was supplemented with appropriate dilutions of a stock solution of a balanced mixture of sea salts (Subov, 1931) containing ( $\left.\mathrm{g}^{-1}\right) \mathrm{NaCl}$ (243), $\mathrm{MgCl}_{2} .6 \mathrm{H}_{2} \mathrm{O}$ (21), $\mathrm{MgSO}_{4} .7 \mathrm{H}_{2} \mathrm{O}(28 \cdot 8), \mathrm{CaCl}_{2} .2 \mathrm{H}_{2} \mathrm{O}(1.08), \mathrm{KCl}(6), \mathrm{NaHCO}_{3}(0 \cdot 18)$ and $\mathrm{NaBr}(0.078)$ to give media with final concentrations of $5-25 \%(\mathrm{w} / \mathrm{v})$ total salts, equivalent to $0 \cdot 7-3 \cdot 5 \mathrm{M}-\mathrm{NaCl}$.

Cultures were grown in $100 \mathrm{ml}$ of medium contained in $250 \mathrm{ml}$ Erlenmeyer flasks shaken at 100 r.p.m. in a Gallenkamp gyrorotatory incubator at $30^{\circ} \mathrm{C}$. Growth was monitored by measurement of optical density at $500 \mathrm{~nm}$ using a spectrophotometer (Novospec, LKB). Stock cultures were maintained on the same liquid medium containing $10 \%$ total salts, solidified with agar $(2 \%, w / v)$, and sub-cultured at weekly intervals; freshly inoculated slopes or plates were grown for $2 \mathrm{~d}$ at $30^{\circ} \mathrm{C}$ and stored at room temperature.

Salinity shift-up. Exponentially growing cultures were shifted-up from 0.7 to $2 \cdot 1 \mathrm{M}-\mathrm{NaCl}$ using the method of Russell et al. (1985). Briefly, this involved minimum centrifugation to collect bacteria and gentle resuspension in prewarmed growth medium. Two types of control were performed in which cultures were grown and resuspended in $0.7 \mathrm{M}-\mathrm{NaCl}$ (pre-shift control) or $2.1 \mathrm{M}-\mathrm{NaCl}$ (post-shift control). Following shift-up, cultures resumed exponential growth immediately at the same rate as post-shift controls.

Preparation of cell-free extracts. Liquid batch cultures were grown to the required growth phase and the bacteria collected by centrifugation at approx. $7000 \mathrm{~g}_{\mathrm{av}}$ for $10 \mathrm{~min}$.

The bacterial pellets were resuspended in a volume of $100 \mathrm{mM}$ potassium phosphate buffer, $\mathrm{pH} 7 \cdot 6$, which was equivalent to $1 / 10$ th of the original culture volume. Compatible solutes were predissolved at the appropriate concentration in this buffer solution as required. The bacteria were broken by two passages through a French pressure cell (Aminco) at $44 \mathrm{MPa}$ pressure. Cellular breakage was estimated by phase-contrast light microscopy to be $>99 \%$. It was not necessary to remove the residual intact bacteria because they are impermeable to the radioactive precursor used to assay CFA synthetase activity (vide infra). The lysates were used the same day for determination of CFA synthetase activity.

Assay of cyclopropane fatty acid synthetase. Attempts were made to assay CFA synthetase activity in intact bacteria by incubating growing cultures or washed cell suspensions with radiolabelled sodium acetate. However, although the major fatty acids, 16:0, 16:1 and 18:1, were labelled, there was very little radioactivity detected in the CFA (data not shown). Therefore, it was decided to use cell-free lysates.

CFA synthetase activity was measured by incubating lysates with $S$ adenosyl-L-[methyl $\left.-{ }^{14} \mathrm{C}\right]$ methionine (Amersham; final concn $3.7 \mathrm{kBq}$ $\mathrm{ml}^{-1}$, specific radioactivity $2.22 \mathrm{GBq} \mathrm{mmol}{ }^{-1}$ ) with shaking at $30^{\circ} \mathrm{C}$. The reaction was stopped by mixing with an equal volume of $\mathrm{KOH}$ $(40 \%, w / v)$. This mixture was heated at $70^{\circ} \mathrm{C}$ for $1 \mathrm{~h}$ which releases the fatty acids by saponification. After cooling, an equal volume of water was added, and the solution was acidifed to $\mathrm{pH}<2$ using approx. $6 \mathrm{M}$ $\mathrm{HCl}$. The fatty acids were extracted with three aliquots of light petroleum (b.p. $40-60^{\circ} \mathrm{C}$ ) and the combined extracts placed in plastic scintillation vials. The solvent was evaporated and $10 \mathrm{ml}$ of scintillant (FisoFluor ' 1', Fisons) added and the radioactivity determined using a LKB Rackbeta liquid-scintillation counter programmed with an external-standard channels-ratio facility for the estimation of counting efficiency. CFA synthetase activity was expressed as 'd.p.m. ${ }^{14} \mathrm{C}$ radioactivity incorporated (mg lysate protein $)^{-1}$. Although there were differences in the activity of individual lysates prepared from separate cultures, the variation in replicate determinations for any one lysate was $<5 \%$ and the trends observed (e.g. in the effects of compatible solutes) were consistently reproducible. Protein concentration was measured using the modification of the Lowry method described by Markwell et al. (1978).

Lipid extraction and analysis. For the determination of bacterial fatty acid composition, cellular lipids were extracted with chloroform/ methanol mixtures using the method of Bligh and Dyer as described by Kates (1986). The chloroform extracts containing total lipid were evaporated to dryness under nitrogen gas and redissolved in fresh chloroform. Aliquots of this extract were used for the preparation of fatty acid methyl esters by transmethylation using conc. $\mathrm{H}_{2} \mathrm{SO}_{4}(2.5 \%$, 
$\mathrm{v} / \mathrm{v}$ ) in dry $\mathrm{MeOH}$ (Russell \& Volkman, 1980). The fatty acid composition was determined by gas-liquid chromatography using a Perkin-Elmer F33 gas chromatograph equipped with glass columns packed with $10 \%$ SP2330 on 100-120 Supelcoport (Supelco) as the stationary phase. Separations were performed isothermally at $170^{\circ} \mathrm{C}$.

Radio-GLC was performed using a Pye-Unicam GCD gas chromatograph equipped with a flame ionization detector and connected to a Raga Raytest detector system (LabLogic, Sheffield, UK) utilizing a gas-flow proportional counter. The injector and detector temperatures were $200^{\circ} \mathrm{C}$, and the oven temperature was $170^{\circ} \mathrm{C}$. The carrier gas was $5 \%(\mathrm{v} / \mathrm{v}) \mathrm{CO}_{2} /$ argon. Fatty acid methyl esters were separated isothermally at $170^{\circ} \mathrm{C}$ on a glass column $(1.5 \mathrm{~m} \times 5 \mathrm{~mm}$ i.d.) packed with $5 \%(\mathrm{w} / \mathrm{w}) \mathrm{SP}-2100$ on $100 / 120$ Supelcoport (Supelco).

\section{Results}

\section{Fatty acid composition}

Cultures of Pseudomonas halosaccharolytica were grown in liquid medium containing $5-25 \%$ total salts, equivalent to $0 \cdot 7-3.5 \mathrm{M}-\mathrm{NaCl}$, and harvested at the end of the exponential phase and $48 \mathrm{~h}$ after entering the stationary phase (Fig. 1) for the determination of fatty acid compositions which are given in Table 1 . There was little effect of an increase in salinity from 0.7 to $1.4 \mathrm{M}$ $\mathrm{NaCl}$ on the growth rate of cultures; at higher concentrations there was a decrease in growth rate and, particularly at the highest salinities a marked increase in the length of the lag period before exponential growth commenced (Fig. 1). Further increases in salt concentration gave larger increases in the lag period and slower exponential growth rates.

There was an increase in the proportion of CFA as the

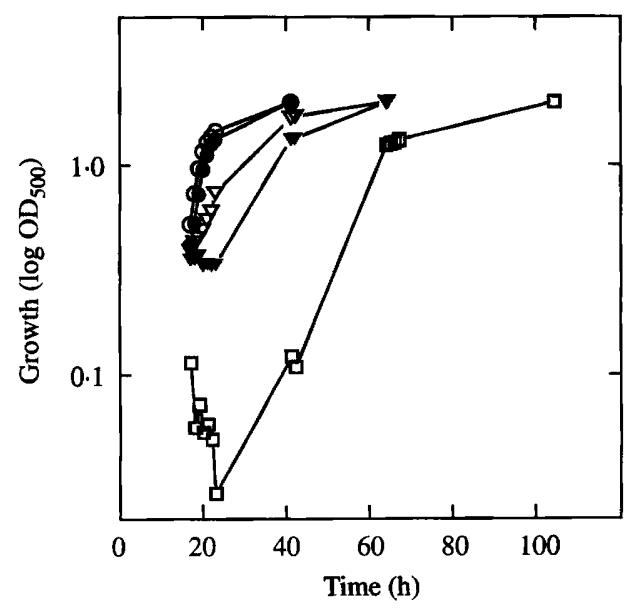

Fig. 1. Effect of salinity on growth of $P$. halosaccharolytica. Batch cultures were grown at $30^{\circ} \mathrm{C}$ in a rich medium (see Methods for composition) containing $5-25 \%(\mathrm{w} / \mathrm{v})$ of a balanced mixture of sea salts, equivalent to $0.7(0), 1.4(\bigcirc), 2.1(\nabla), 2.8(\nabla)$ and $3.5(\square) \mathrm{M}-$ $\mathrm{NaCl}$. Culture growth was monitored by optical density measurements at $500 \mathrm{~nm}$. cultures went from the exponential into the stationary phase (Table 1). The addition of salt to the growth medium also resulted in an increase in CFA content, whether cultures were analysed at the end of exponential or in the stationary phase, with the greatest increase in CFA occurring at or above $2 \cdot 1 \mathrm{M}-\mathrm{NaCl}$ (Table 1). The increases in total CFA content were matched by corresponding decreases in total unsaturated fatty acid contents.

\section{Cyclopropane fatty acid synthetase activity}

When lysates prepared in $100 \mathrm{~mm}$-potassium phosphate buffer from cultures grown in $0.7 \mathrm{M}-\mathrm{NaCl}$ were incubated with $S$-adenosyl[methyl- $\left.{ }^{14} \mathrm{C}\right]$-methionine, there was linear incorporation of the radiolabel into fatty acids for up to $3 \mathrm{~h}$, at a rate of approx. 600 d.p.m. $\mathrm{h}^{-1}$ (mg lysate protein) ${ }^{-1}$ (Fig. 2). Changing the buffer composition, including increasing its ionic strength, did not increase this rate of incorporation (data not shown), which was too low for radio-GLC analysis to be used for determining the identity of the radiolabelled fatty acid products. However, when glycinebetaine was added (by breaking bacteria in buffers containing increasing concentrations of the compatible solute) there was a large increase in the incorporation of radioactivity of up to 12fold in $3 \mathrm{M}$-glycinebetaine (Fig. 2). Further increases in compatible solute concentration up to $6 \mathrm{M}$-glycinebetaine did not further stimulate incorporation (Fig. 3).

A number of other organic compatible solutes were tested in lysates of cultures grown in $0.7 \mathrm{M}-\mathrm{NaCl}$ medium, but they did not stimulate CFA synthetase to the same extent as did glycinebetaine (Table 2). Sucrose and trehalose gave 1.8 - and 1.5 -fold increases, respectively, but glycerol, proline and sodium glutamate gave activities that were only marginally greater than those of control lysates prepared in phosphate buffer alone. When lysates were prepared in buffer containing $1 \mathrm{M}$ $\mathrm{NaCl}$, there was $75 \%$ inhibition of CFA synthetase activity, and with $3 \mathrm{M}-\mathrm{NaCl}$ or $-\mathrm{KCl}$ the inhibitions were 89 and $93 \%$, respectively (Table 2 ).

Radio-GLC analysis of the fatty acid products of $S$-adenosyl[ $\left.{ }^{14} \mathrm{C}\right]$ methionine incorporation by lysates showed that $81-85 \%$ of the radioactivity was present in the two CFA, 17:0cyc and 19:0cyc, with the remainder being found in 18:0 and an unknown fatty acid eluting after 19:0cyc (Table 3). The precursor was incorporated into the same products whether lysates were prepared in phosphate buffer containing 1 or $3 \mathrm{M}$-glycinebetaine, from cultures grown in 0.7 or $2.1 \mathrm{M}-\mathrm{NaCl}$ medium (Table 3).

The specific activities of CFA synthetase in lysates prepared from cultures grown in 0.7 and $2 \cdot 1 \mathrm{M}-\mathrm{NaCl}$ were compared in the presence of 1 and $3 \mathrm{M}$ - 
Table 1. The effect of culture age and salinity on the fatty acid composition (wt \%) of P. halosaccharolytica

Cultures were grown in broth medium containing $0 \cdot 7-3 \cdot 5 \mathrm{M}-\mathrm{NaCl}$ as indicated (equivalent to $5-25 \%, w / v$, total salts) and harvested at the end of the exponential phase and $24 \mathrm{~h}$ after entering stationary phase for lipid extraction and preparation of fatty acid methyl esters by GLC analysis as described in Methods. Abbreviations: tr., < $0.1 \%$; exp, exponential phase of growth; stat, stationary phase of growth.

\begin{tabular}{|c|c|c|c|c|c|c|c|c|c|c|}
\hline \multirow[b]{3}{*}{$\begin{array}{l}\text { Growth phase... } \\
\text { Fatty } \\
\text { acid }\end{array}$} & \multicolumn{10}{|c|}{$\begin{array}{l}\text { Fatty acid composition (wt \%) at equivalent concn of } \mathrm{NaCl}(\mathrm{M}) \text { in culture } \\
\text { medium }\end{array}$} \\
\hline & \multicolumn{2}{|c|}{0.7} & \multicolumn{2}{|c|}{$1 \cdot 4$} & \multicolumn{2}{|c|}{$2 \cdot 1$} & \multicolumn{2}{|c|}{$2 \cdot 8$} & \multicolumn{2}{|c|}{$3 \cdot 5$} \\
\hline & Exp & Stat & Exp & Stat & Exp & Stat & Exp & Stat & Exp & Stat \\
\hline $16: 0$ & $43 \cdot 1$ & $47 \cdot 8$ & $43 \cdot 4$ & $50 \cdot 7$ & $38 \cdot 6$ & $44 \cdot 1$ & $52 \cdot 1$ & 39.8 & $61 \cdot 0$ & $46 \cdot 2$ \\
\hline $16: 1$ & 6.8 & 3.0 & 6.9 & $2 \cdot 8$ & 6.6 & 0.2 & 1.0 & tr. & $0 \cdot 2$ & tr. \\
\hline $17: 0$ cyc & 0.2 & $5 \cdot 1$ & 0.7 & $5 \cdot 1$ & $1 \cdot 1$ & $11 \cdot 2$ & $10 \cdot 6$ & 11.9 & $10 \cdot 3$ & $12 \cdot 7$ \\
\hline $18: 0$ & 0.7 & 0.8 & 0.5 & $2 \cdot 2$ & 0.6 & 0.8 & 0.3 & 0.3 & tr. & 0.3 \\
\hline $18: 1$ & $44 \cdot 5$ & 11.9 & 37.6 & $9 \cdot 2$ & 38.6 & $1 \cdot 4$ & $2 \cdot 2$ & 0.4 & $2 \cdot 0$ & tr. \\
\hline $19: 0$ cyc & $4 \cdot 7$ & 31.4 & $10 \cdot 8$ & $30 \cdot 1$ & $14 \cdot 7$ & $42 \cdot 1$ & 33.7 & $47 \cdot 5$ & $34 \cdot 6$ & $40 \cdot 7$ \\
\hline
\end{tabular}

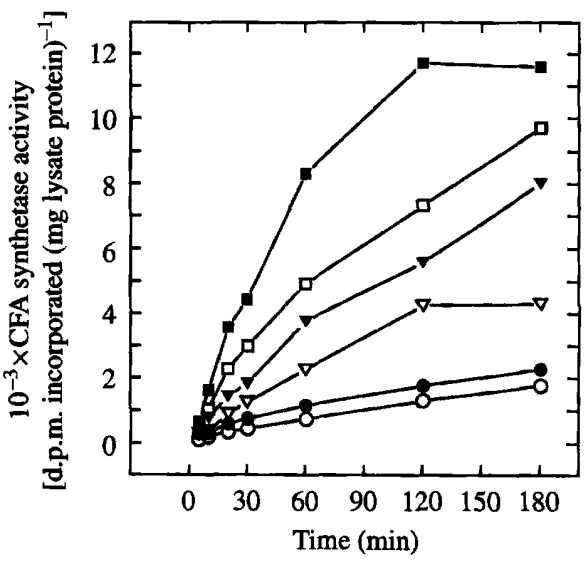

Fig. 2

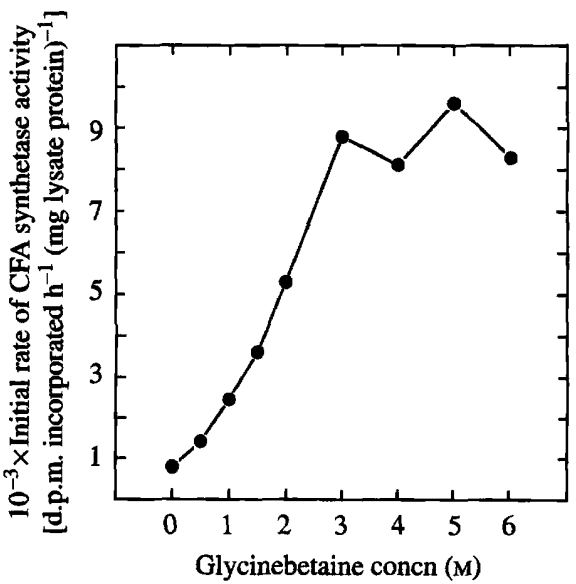

Fig. 3

Fig. 2. Effect of glycinebetaine on the incorporation of $S$-adenosyl-L-[methyl- $\left.{ }^{14} \mathrm{C}\right]$ methionine in CFA by cell-free lysates of $P$. halosaccharolytica. Cultures were grown in $5 \%(\mathrm{w} / \mathrm{v})$ total sea salts, equivalent to $0.7 \mathrm{M}-\mathrm{NaCl}$, to the end of exponential phase. Harvested bacteria were resuspended in $100 \mathrm{mM}$-potassium phosphate buffer, $\mathrm{pH} 7 \cdot 6$, alone $(O)$ or containing $0.5(\Theta), 1.0(\nabla), 1 \cdot 5(\nabla)$, $2.0(\square)$ and $3.0(\square)$ M-glycinebetaine, and cell-free lysates prepared by breaking the bacteria with a French press. CFA synthetase activity was determined by the incorporation of $S$-adenosyl-L-[methyl $\left.-{ }^{14} \mathrm{C}\right]$ methionine (see Methods) and is expressed as 'd.p.m. incorporated (mg lysate protein) $)^{-1}$.

Fig. 3. Effect of glycinebetaine on the activity of CFA synthetase in cell-free lysates of $P$. halosaccharolytica. Cell-free lysates were

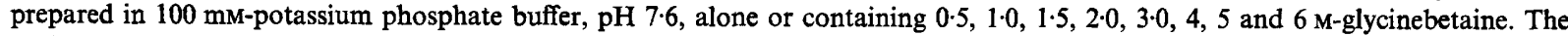
initial rate of CFA synthetase activity was determined and is expressed as 'd.p.m. incorporated $\mathrm{h}^{-1}$ ( $\mathrm{mg}$ lysate protein) ${ }^{-1}$ '.

glycinebetaine (Fig. 4). Glycinebetaine stimulated the activity of both enzyme preparations, and although the activities in $3 \mathrm{M}$-glycinebetaine were very similar, in $1 \mathrm{M}$ glycinebetaine the lysates from low-salinity cultures gave higher activities compared with those of the high-salinity cultures (Fig. 4).

\section{Effect of salinity shift-up on cyclopropane fatty acid synthetase activity}

Cultures growing in $0.7 \mathrm{M}-\mathrm{NaCl}$ medium were shiftedup to $2 \cdot 1 \mathrm{M}-\mathrm{NaCl}$ and the activity of CFA synthetase determined in lysates prepared in 1 and $3 \mathrm{M}$ - 
Table 2. The effect of some salts and organic compatible solutes on CFA synthetase activity in lysates of $P$. halosaccharolytica

Cultures were grown in broth medium containing $0.7 \mathrm{M}-\mathrm{NaCl}$ (equivalent to $5 \%$ total salts) and harvested in late exponential phase for the preparation of lysates by breaking bacteria in $0.1 \mathrm{M}$ phosphate buffer alone ('none') or containing the solute indicated. The activity of CFA synthetase is expressed as 'd.p.m. incorporated $\mathrm{h}^{-1}$ (mg lysate protein) $)^{-1}$.

\begin{tabular}{lc}
\hline \multicolumn{1}{c}{ Addition } & $\begin{array}{c}\text { CFA synthetase } \\
\text { activity }\end{array}$ \\
\hline None & 712 \\
$1 \mathrm{M}-\mathrm{NaCl}$ & 180 \\
$3 \mathrm{M}-\mathrm{NaCl}$ & 75 \\
$3 \mathrm{M}-\mathrm{KCl}$ & 47 \\
$1 \mathrm{M}-\mathrm{Glycinebetaine}$ & 3041 \\
$3 \mathrm{M}-$ Glycinebetaine & 7488 \\
$3 \mathrm{M}-$ Trehalose & 1040 \\
$3 \mathrm{M}-$ Sucrose & 1302 \\
$3 \mathrm{M}-$ Glycerol & 897 \\
$3 \mathrm{M}-$ Proline & 851 \\
$3 \mathrm{M}-$ Sodium glutamate & 751 \\
\hline
\end{tabular}

Table 3. Effect of culture medium salinity and glycinebetaine concentration on the percentage distribution of radioactivity from $S$ adenosyl $\left[{ }^{14} \mathrm{C}\right]$ methionine in fatty acids synthesized by lysates of $P$. halosaccharolytica

Cultures were grown in broth medium at the salinities indicated and cell-free lysates prepared by breaking bacteria in buffer containing 1 or $3 \mathrm{M}$-glycinebetaine as shown. Lysates were incubated for $2 \mathrm{~h}$ with $S$-adenosyl $\left[{ }^{14} \mathrm{C}\right]$ methionine and the lipid fatty acids analysed by radio-GLC as described in Methods. There were no significant differences between the fatty acid mass compositions of lysates and the intact bacteria from which they were derived (the latter are given in Table 1).

\begin{tabular}{|c|c|c|c|c|c|}
\hline \multirow{3}{*}{$\begin{array}{l}\text { Fatty } \\
\text { acid }\end{array}$} & \multirow{3}{*}{$\begin{array}{l}\text { Glycinebetaine } \\
\text { concn (M) ... }\end{array}$} & \multicolumn{4}{|c|}{$\begin{array}{l}\text { Distribution of radioactivity in fatty } \\
\text { acids at equivalent concn of } \mathrm{NaCl}(\mathrm{M} \\
\text { in culture medium }\end{array}$} \\
\hline & & \multicolumn{2}{|c|}{0.7} & \multicolumn{2}{|c|}{$2 \cdot 1$} \\
\hline & & 1 & 3 & 1 & 3 \\
\hline $16: 1$ & & ND & ND & ND & ND \\
\hline $16: 0$ & & tr. & tr. & tr. & tr. \\
\hline 17:0cyc & & $12 \cdot 1$ & 8.9 & $10 \cdot 6$ & $17 \cdot 1$ \\
\hline 18:1 & & ND & ND & ND & ND \\
\hline $18: 0$ & & $5 \cdot 1$ & $6 \cdot 2$ & 6.6 & $4 \cdot 3$ \\
\hline 19:0сус & & $69 \cdot 2$ & 73.8 & 70.4 & 67.9 \\
\hline Unknown & & $13 \cdot 6$ & $11 \cdot 2$ & $12 \cdot 4$ & $10 \cdot 7$ \\
\hline
\end{tabular}

Abbreviations: ND, not detected; tr., trace, $<0.1 \%$.

glycinebetaine 2 and $6 \mathrm{~h}$ after the shift (Table 4). Controls were performed in which cultures growing in 0.7 or $2.1 \mathrm{M}-\mathrm{NaCl}$ underwent exactly the same 'shift-up' procedures except that the bacteria were resuspended in

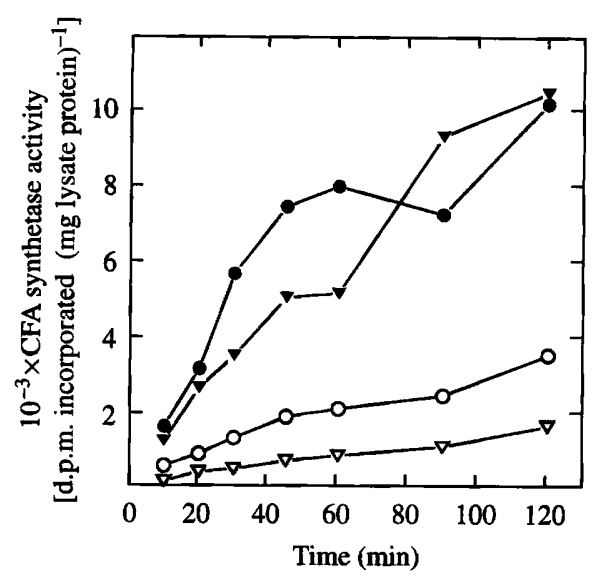

Fig. 4. Effect of glycinebetaine on the activity of CFA synthetase in cellfree lysates of $\boldsymbol{P}$. halosaccharolytica grown at different salinities. Cellfree lysates of cultures growing in $0.7(\mathrm{O}, 0)$ or $2 \cdot 1(\nabla, \nabla) \mathrm{M} \cdot \mathrm{NaCl}$ were prepared as described in the legend to Fig. 3. The lysate buffer contained 1.0 (open symbols) or $\mathbf{3 . 0}$ (filled symbols) M-glycinebetaine. CFA synthetase activity is expressed as 'd.p.m. incorporated (mg lysate protein) $)^{-1}$.

Table 4. Effect of a shift-up in culture medium salinity on the CFA synthetase activity in P. halosaccharolytica

Cultures were grown in broth medium containing $0.7 \mathrm{M}-\mathrm{NaCl}$ ('low salt') or $2 \cdot 1 \mathrm{M}-\mathrm{NaCl}$ ('high salt'), equivalent to $5 \%$ and $15 \%$ total salts concentration. In mid-exponential phase all cultures were harvested; half of the low-salt cultures were shifted-up to high-salt as described in Methods and the remaining low-salt cultures were subjected to the same handling procedure except that the bacteria were finally resuspended in low-salt medium ("low-salt control'); comparable 'high-salt controls' were prepared from the cultures growing in high-salt medium. All cultures resumed exponential growth without any lag period. After a further 2 or $6 \mathrm{~h}$ growth cell-free lysates were prepared in 1 and $3 \mathrm{M}$ glycinebetaine-containing buffers for the shifted and both control cultures. The CFA synthetase activity was measured and is given as 'd.p.m. incorporated $h^{-1}$ (mg lysate protein) $)^{-1}$ '.

\begin{tabular}{lrc}
\hline & \multicolumn{2}{c}{ CFA synthetase activity } \\
\cline { 3 - 3 } \multicolumn{1}{c}{ Time after shift-up (h) ... } & \multicolumn{1}{c}{2} & \multicolumn{1}{c}{6} \\
\hline (a) 1 M-glycinebetaine & & \\
Shift-up & 9555 & 9039 \\
Low-salt control & 24181 & 25730 \\
High-salt control & 13682 & 14152 \\
(b) 3 M-glycinebetaine & & \\
Shift-up & 79955 & 58452 \\
Low-salt control & 109355 & 120696 \\
High-salt control & 53840 & 64592 \\
\hline \hline
\end{tabular}

fresh growth medium having the same salinity as the corresponding pre-shift culture (Table 4). The CFA synthetase activities of lysates prepared in $3 \mathrm{M}$ glycinebetaine measured 2 and $6 \mathrm{~h}$ after a shift-up were 73 and $48 \%$, respectively, compared with the pre-shift 
salinity controls; in contrast, the activities of these 'shifted lysates' were 149 and $91 \%$, respectively, compared with the post-shift salinity controls. In both the shifted and control lysates there was a marked stimulation of CFA synthetase activity by glycinebetaine, ranging from 4- to 8-fold.

\section{Discussion}

Pseudomonas halosaccharolytica was chosen for the present study, since it was known to accumulate CFA in its membrane lipids in response to an elevation in culture medium salinity (Ohno et al., 1979). The present data demonstrate the interplay between culture age and salinity on CFA content, which was important to establish under our cultural conditions before studying the effects of compatible solutes on CFA synthetase activity since it was necessary to ensure that cultures were harvested at clearly defined stages of the growth cycle in batch culture. Salt concentrations of 0.7 and $2.1 \mathrm{M}$ were chosen as a suitably wide range (3-fold difference) within which salinity had only a small effect on the exponential growth rate (Fig. 1), since growth rate changes could also influence fatty acid composition. Thus we were able to study the effects of salt and compatible solutes on CFA synthetase activity in vitro in lysates prepared from cultures which had been grown at the same rate but in different salinities and with different fatty acid compositions.

Since CFA accumulate in a salt-dependent manner, it had been anticipated that we should find that the specific activity of CFA synthetase would be greater in lysates prepared from cultures grown in $2 \cdot 1 \mathrm{M}-\mathrm{NaCl}$ compared with those grown in $0.7 \mathrm{M}-\mathrm{NaCl}$. When account is taken of the (presumed) total intracellular concentration of compatible solutes, this was indeed the finding, there being 2-3-fold more activity at the higher salinity. However, most of this difference appears to be due to the stimulation by glycinebetaine, although the enzymes from low- and high-salinity cultures did react differently to $\mathrm{NaCl}$ in that much lower activities were obtained at low salinity with the lysates from $2 \cdot 1 \mathrm{M}-\mathrm{NaCl}$ compared with $0.7 \mathrm{M}-\mathrm{NaCl}$-grown cultures (Fig. 3). Clearly the enzymes react differently and there is a marked effect of the compatible solute, but it is difficult to draw more precise conclusions because it was not possible to mimic more closely the intracellular compatible solute composition. The cells would have contained ectoine as well as glycinebetaine when grown in the broth medium (Severin et al., 1992). However, we did not have ectoine available to add to lysates, although they would have contained some of the endogenous compounds which remain during cell breakage. Therefore, both the composition and total concentration of compatible solutes in lysates are approximations.

In order to investigate further the relationship between CFA synthetase activity and culture medium salinity, shift-up experiments were performed. There was no lag period following a shift-up from 0.7 to $2.1 \mathrm{M}-\mathrm{NaCl}$ and, after the shift, cultures resumed exponential growth at essentially the same rate. It was decided to sample cultures 2 and $6 \mathrm{~h}$ after the shift-up, because this was known to cover the early and later stages of the adaptive process in respect of changes in fatty acid composition. However, over this time-scale we did not observe any adaptive changes in CFA synthetase activity. It appeared that within $2 \mathrm{~h}$ after the shift, the enzyme responded in a manner more like that of cultures grown in the postshift salt concentration, and that the major determinant of enzyme activity was the compatible solute concentration. The time-scale of changes in the intracellular concentrations of glycinebetaine and ectoine in this bacterium is not known, but the data obtained with cellfree lysates indicate that enzyme activity would respond immediately to any changes and that enzyme induction would not be necessary to achieve the changes in fatty acid composition.

A major function of the organic compatible solutes which are accumulated inside micro-organisms in response to salinity is assumed to be the balancing of osmotic pressures outside and inside the cell, although exactly equivalent balancing has not been proven for any organism. Morever, it is not clear whether they have any other function(s) inside cells. Their accumulation to high concentrations inside cells means that they must at the very least not interfere with the activity of intracellular protein and other macromolecular functions. There are several theories of how compatible solutes achieve their functions and, although none provide a conclusive explanation, it is clear that the maintenance of protein hydration becomes critical for halophiles growing in high salinities, assuming that they maintain osmotic equilibrium between the cytoplasm and the culture medium (Trüper \& Galinski, 1990). A mechanism proposed for glycinebetaine is that it functions as a compatible solute by acting on the cluster structure of water and thereby indirectly influences the hydration of proteins. The present data show that glycinebetaine, one of the major compatible solutes which are accumulated by $P$. halosaccharolytica cultured in complex growth media (Severin et al., 1992), has a marked positive effect on CFA synthetase activity. Therefore, whatever the molecular explanation for glycinebetaine action in this organism, it clearly is not a passive one; moreover, it is selective in the sense that other organic compatible solutes which are found in different halophilic micro- 
organisms stimulate CFA synthetase activity of $P$. halosaccharolytica much less or only marginally. Compatible solutes such as glycinebetaine (Pollard \& Wyn Jones, 1979) and ectoine (Lippert \& Galinski, 1992) are known to be capable of stabilizing enzyme activities, but it is not known if this plays a specific role during osmo(halo)adaptation. If the naturally accumulated compatible solute stimulates other enzymes, besides CFA synthetase, which are involved in osmo(halo)adaptation to the same extent or differentially, this would be a major factor in the regulation of intracellular metabolism during this process and would necessitate a revision of ideas about the functional significance of the interactions of compatible solutes with cellular proteins.

In marked contrast with the organic compatible solutes, $\mathrm{NaCl}$ and $\mathrm{KCl}$ strongly inhibited $\mathrm{CFA}$ synthetase, despite the fact that bacteria were grown in the presence of $>0.7 \mathrm{M}-\mathrm{NaCl}$. Salt is known to inhibit the activities of a number of intracellular enzymes in moderately halophilic eubacteria and optimum salt concentrations in the range $0 \cdot 1-0 \cdot 6 \mathrm{M}-\mathrm{NaCl}$ have been reported (Kamekura, 1986). The only comparable published data on fatty acid synthetases is that of Pugh et al. (1971) who observed that a cell-free preparation of the fatty acid synthetase from Escherichia coli was $90 \%$ inhibited by $1 \mathrm{M}-\mathrm{NaCl}$. In addition, we have observed similar levels of inhibition by salt of the fatty acid synthetase in Vibrio costicola (M. Kogut and N. J. Russell, unpublished data). This inhibition is probably a result of the high ionic strength, rather than a specific effect of $\mathrm{Na}^{+}$, because we observed a comparable inhibition by $\mathrm{KCl}$. It is not surprising that the fatty acid synthetase from $V$. costicola is sensitive to high concentrations of $\mathrm{NaCl}$ or $\mathrm{KCl}$ because we have shown recently that the intracellular $\mathrm{Na}^{+}$concentration in this moderately halophilic eubacterium is approximately $200 \mathrm{~mm}$ when the external salinity is $1 \mathrm{M}$ (Gilboa et al., 1991). Assuming that there is a comparably low $\mathrm{Na}^{+}$ concentration inside cells of $\boldsymbol{P}$. halosaccharolytica, the intracellular enzymes would not be adapted to conditions of high salinity. This is in direct contrast to the situation in extreme halophiles. In eubacterial halophiles, such as those discussed here, which accumulate organic compatible solutes, the intracellular environment appears to be similar to that of non-halophilic eubacteria which are also known to accumulate similar compounds although to much lower concentrations. The present data indicate that these organic compatible solutes may have another important function besides their role in osmotic balance, namely that they activate enzymes involved in osmo(halo)adaptation - they do not simply preserve enzyme activity through protein stabilization, as was believed previously. In the context of osmo(halo)regulation it will interesting to determine whether this stimulation of enzyme activity is specific to key enzymes involved in this process.

The authors wish to thank The Nuffield Foundation for a grant (to N.J.R.), and Instituto Britanico and Ministerio de Educacion y Ciencia (Spain) for a Fleming Award Fellowship (to M.M.S.) to enable M.M.S. to work in Cardiff where the experimental work was performed.

\section{References}

Cronan, J. E., JR, ReEd, R., TAYloR, F. R. \& JaCKson, M.B. (1979). Properties and biosynthesis of cyclopropane fatty acids in Escherichia coli. Journal of Bacteriology 138, 118-121.

Csonka, L. N. (1989). Physiological and genetic responses of bacteria to osmotic stress. Microbiological Reviews 53, 121-147.

Csonka, L. N. \& Hanson, A. D. (1991). Prokaryotic osmoregulation: genetics and physiology. Annual Review of Microbiology 45, 569-606.

Gilboa, H., Kogut, M., Chalamish, S., Regev, R., Avi-Dor, Y. \& RUSSELl, N. J. (1991). Use of ${ }^{23} \mathrm{Na}$ nuclear magnetic resonance spectroscopy to determine the true intracellular concentration of free sodium in a halophilic eubacterium. Journal of Bacteriology 173, $7021-7023$.

HaRwood, J. L. \& Russell, N. J. (1984). Lipids in Plants and Microbes. London: George Allen \& Unwin.

IMHOFF, J. F. (1986). Osmoregulation and compatible solutes in eubacteria. FEMS Microbiology Reviews 39, 57-66.

Jarrell, H. C., Tulloch, A. P. \& Smith, I. C. P. (1983). Relative roles of cyclopropane-containing and cis-unsaturated fatty acids in determining membrane properties of Acholeplasma laidlawii: a deuterium nuclear magnetic resonance study. Biochemistry 22, $5611-5619$.

KaMEKura, E. (1986). Production and function of enzymes of eubacterial halophiles. FEMS Microbiology Reviews 39, 145-150.

KATES, M. (1986). Techniques of Lipidology, 2nd edn. Amsterdam: Elsevier.

KusHNER, D. J. (1978). Life in high salt and solute concentrations: halophilic bacteria. In Microbial Life in Extreme Environments, pp. 317-368. Edited by D. J. Kushner. London: Academic Press.

LARSEN, H. (1986). Halophilic and halotolerant microorganisms - an overview and historical perspective. FEMS Microbiological Reviews 39, 3-7.

LIPPERT, K. \& GALINSKI, E. A. (1992). Enzyme stabilization by ectoinetype compatible solutes: protection against heating, freezing and drying. Applied Microbiology and Biotechnology 37, 61-65.

Macdonald, P. M., Sykes, B. D. \& McElhaney, R. N. (1985). Fluorine-19 nuclear magnetic resonance studies of lipid fatty acyl chain order and dynamics in Acholeplasma laidlawii B membranes. A direct comparison of the effects of cis and trans cyclopropane ring and double-bond substituents on orientational order. Biochemistry 24, 4651-4659.

Markwell, M. A. K., HaAs, S. M., Bieber, L. L. \& Tolbert, N. E. (1978). A modification of the Lowry procedure to simplify protein determination in membrane and lipoprotein samples. Analytical Biochemistry 87, 206-210.

Moore, W. E. C., Cato, E. P. \& Moore, L. V. H. (1985). Index of the bacterial and yeast nomenclature changes published in the International Journal of Systematic Bacteriology since the 1980 Approved Lists of Bacterial Names (1 January 1980 to 1 January 1985). International Journal of Systematic Bacteriology 35, 382-407.

Monteoliva-SANChez, M. \& Ramos-CormenZana, A. (1987). Cellular fatty acid composition in moderately halophilic Gram-negative rods. Journal of Applied Bacteriology 62, 361-366.

OHNO, Y., YANO, I, \& MASUI, M. (1979). Effect of $\mathrm{NaCl}$ concentration and temperature on the phospholipid and fatty acid compositions of a moderately halophilic bacterium, Pseudomonas halosaccharolytica. Journal of Biochemistry 85, 413-421.

Pollard, A. \& WYN JONES, R. G. (1979). Enzyme activities in concentrated solutions of glycine betaine and other solutes. Planta 144, 291-298.

Pugh, E. L., Wassef, M. K. \& Kates, M. (1971). Inhibition of fatty 
acid synthetase in Halobacterium cutirubrum and Escherichia coli by high salt concentrations. Canadian Journal of Biochemistry 49, 953-958.

Regev, R., Peri, I., Gllboa, H. \& Avi-Dor, Y. (1990). ${ }^{13}$ C NMR study of the interrelation between synthesis and uptake of compatible solutes in two moderately halophilic eubacteria: bacterium $\mathrm{Ba}_{1}$ and Vibrio costicola. Archives of Biochemistry and Biophysics 278, 106-112.

Russel., N. J. (1989a). Adaptive modifications in membranes of halotolerant and halophilic microorganisms. Journal of Bioenergetics and Biomembranes 21, 93-113.

Russell, N. J. $(1989 b)$. Functions of lipids: structural roles and membrane functions. In Microbial Lipids, vol. 2, Chapter 17, pp. 279-365. Edited by S. G. Wilkinson \& C. Ratledge. London: Academic Press.

Russell, N. J. (1992). Lipids of halophilic and halotolerant microorganisms. In The Biology of Halophilic Bacteria, Chapter 7, pp. 163-210. Edited by R. H. Vreeland \& L. Hochstein. Boca Raton: CRC Press.

Russell, N. J. \& KoGUT, M. (1985). Haloadaptation: salt sensing and cell-envelope changes. Microbiological Sciences 2, 345-350.

Russell, N. J. \& VolKMAN, J. K. (1980). The effect of temperature on wax ester composition in the psychrophilic bacterium Micrococcus cryophilus ATCC 15174. Journal of General Microbiology 118, 131-141.
Russell, N. J., Kogut, M. \& Kates, M. (1985). Phospholipid biosynthesis in the moderately halophilic bacterium Vibrio costicola during adaptation to changing salt concentrations. Journal of General Microbiology 131, 781-789.

Sevirin, J., Wohlfarth, A. \& Galinski, E. A. (1992). The predominant role of recently discovered tetrahydropyrimidines for the osmoadaptation of halophilic eubacteria. Journal of General Microbiology 138, 1629-1638.

Skerman, V. B. D., McGowan, V. \& SNeath, P. H. A. (editors) (1980). Approved Lists of Bacterial Names. International Journal of Systematic Bacteriology 30, 225-420.

Stock, J. B., NinfA, A. \& STOCK, A. M. (1989). Protein phosphorylation and regulation of adaptive responses in bacteria. Microbiological Reviews 53, 450-490.

SuBov, N. N. (1931). Oceanographical Tables. USSR Oceanographical Institute, Hydrometeorological Communications, Moscow.

TrüPER, H. G. \& GalinskI, E. A. (1990). Compatible solutes in halophilic phototrophic procaryotes. In Microbial Mats. Physiological Ecology of Benthic Microbial Communities, pp. 342-348. Edited by Y. Cohen \& E. Rosenberg. Washington DC: American Society for Microbiology.

Wohlfarth, A., Severin, J. \& Galinski, E. A. (1990). The spectrum of compatible solutes in heterotrophic halophilic eubacteria of the family Halomonadaceae. Journal of General Microbiology 136, 705-712. 